\title{
MIXED-METAL COMPLEXES OF MIXED-VALENT DINUCLEAR RUTHENIUM(II,III) CARBOXYLATE AND TETRACYANIDONICKELATE(II)
}

\author{
Masahiro Mikuriya $^{\mathrm{a}^{*}}$, Yusuke Tanaka ${ }^{\mathrm{a}}$, Daisuke Yoshioka ${ }^{\mathrm{a}}$, Makoto Handa ${ }^{\mathrm{b}}$ \\ ${ }^{a}$ Department of Chemistry and Research Center for Coordination Molecule-based Devices, School of Science and Technology, \\ Kwansei Gakuin University, 2-1 Gakuen, Sanda 669-1337, Japan \\ ${ }^{b}$ Department of Chemistry, Interdisciplinary Graduate School of Science and Engineering, Shimane University, 1060 Nishikawatsu, \\ Matsue 690-8504, Japan \\ *e-mail: junpei@kwansei.ac.jp, phone: (+81 79) 56583 65; fax: (+81 79) 5659077
}

\begin{abstract}
Mixed-metal chain complexes constructed from lantern-type dinuclear ruthenium(II,III) carboxylate unit and tetracyanidonickelate(II), $\left(\mathrm{PPh}_{4}\right)_{n}\left[\mathrm{Ru}_{2}\left(\mathrm{O}_{2} \mathrm{CCH}_{3}\right)_{4} \mathrm{Ni}(\mathrm{CN})_{4}\right]_{n} \cdot n \mathrm{H}_{2} \mathrm{O} \quad$ (1) and $\left(\mathrm{PPh}_{4}\right)_{n}\left[\mathrm{Ru}_{2}\left\{\mathrm{O}_{2} \mathrm{CC}\left(\mathrm{CH}_{3}\right)_{3}\right\}_{4}\right]_{3 n}\left[\mathrm{Ni}(\mathrm{CN})_{4}\right]_{2 n} \cdot 2 n \mathrm{H}_{2} \mathrm{O}(2)$, were synthesized and characterized by elemental analysis, IR, and UV-vis spectroscopies. These data are in accordance with the formation of the chain complex with an alternative arrangement of the dinuclear $\mathrm{Ru}_{2}$ unit and tetracyanidonickelate(II). A broad band at near-IR and a band at visible region (1058 and $452 \mathrm{~nm}$ for 1 and 1082 and $454 \mathrm{~nm}$ for 2) were observed in the diffused reflectance spectra and ascribed to a $\delta\left(\mathrm{Ru}_{2}\right) \rightarrow \delta^{*}\left(\mathrm{Ru}_{2}\right)$ and a $\pi\left(\mathrm{RuO}, \mathrm{Ru}_{2}\right) \rightarrow \pi^{*}\left(\mathrm{Ru}_{2}\right)$ transitions, respectively. Temperature-dependence of magnetic susceptibility $(4.5-300 \mathrm{~K})$ showed that the antiferromagnetic interaction between the dinuclear units is weak $\left(z J=-0.2 \mathrm{~cm}^{-1}\right)$ with $D$ value of $75 \mathrm{~cm}^{-1}$ for both complexes.
\end{abstract}

Keywords: dinuclear ruthenium(II,III) carboxylate, magnetic property, mixed-metal complex, tetracyanido nickelate(II).

\section{Introduction}

The chemistry of dinuclear metal carboxylates has attracted much attention over the past five decades because of the unique lantern-type (or paddlewheel-type) dinuclear core [1-5]. Among the dinuclear metal carboxyletes, mixedvalent ruthenium(II,III) carboxylates $\left[\mathrm{Ru}_{2}\left(\mathrm{O}_{2} \mathrm{CR}\right)_{4}\right]^{+}$are interesting, because these dinuclear systems are paramagnetic with three unpaired electrons on the $\pi^{* 2} \delta^{* 1}$ orbitals in the metal-metal bonds and with large zero-field splitting (ZFS) [3-37]. The dinuclear ruthenium carboxylates show various interesting features such as liquid crystalline properties [25] as well as the paramagnetic properties. We prepared many metal-assembled complexes from dinuclear species to one-dimensional chain compounds by application of linking ligands to dinuclear ruthenium carboxylates and found that most of them are antiferromagnetic between the dinuclear ruthenium units and the strength of the antiferromagnetic interaction depends on the linking ligands [16-29]. About ten years ago, we and Miller's group reported that the dinuclear ruthenium carboxylates form polymeric mixed-metal complexes with hexacyanidometalate ion $\left[\mathrm{M}(\mathrm{CN})_{6}\right]^{3-}$ $(\mathrm{M}=\mathrm{Fe}, \mathrm{Co}$, and so on) and found some of them show an antiferromagnetic interaction between the dinuclear ruthenium units through the diamagnetic hexacyanometalate ion and a ferrimagnetic interaction among the hetero metal ions [30-35]. Recently, our continuing study on these systems led us to mixed-metal complexes with octacyanidometalate ions $\left[\mathrm{M}(\mathrm{CN})_{8}\right]^{4}(\mathrm{M}=\mathrm{W})[36,37]$. In these mixed-metal systems, a ferrimagnetic interaction between the dinuclear $\mathrm{Ru}_{2}$ spins and octacyanidometalate spins was observed for $\left[\left\{\mathrm{Ru}_{2}\left(\mathrm{O}_{2} \mathrm{CC}\left(\mathrm{CH}_{3}\right)_{3}\right)_{4}\right\}_{3}\left(\mathrm{H}_{2} \mathrm{O}\right) \mathrm{W}(\mathrm{CN})_{8}\right]_{n}$ [37]. Therefore, it is important to develop these mixed-metal systems to find interesting molecular magnetic compounds. In this study, we extended these systems to mixed-metal complexes with tetracyanidometalate ion by using tetracyanidonickelate(II) ion $\left[\mathrm{Ni}(\mathrm{CN})_{4}\right]^{2-}$ in order to obtain new metal-assembled complexes of ruthenium(II,III) carboxylate. The isolated complexes were characterized by elemental analysis, IR, UV-vis spectra, and temperature dependence of magnetic susceptibilities $(4.5-300 \mathrm{~K})$. Here, we report on the preparation and structural characterization of these new systems.

\section{Experimental}

Synthesis: $\left[\mathrm{Ru}_{2}\left(\mathrm{O}_{2} \mathrm{CCH}_{3}\right)_{4}\left(\mathrm{H}_{2} \mathrm{O}\right)_{2}\right] \mathrm{BF}_{4}$ and $\left[\mathrm{Ru}_{2}\left\{\mathrm{O}_{2} \mathrm{CC}\left(\mathrm{CH}_{3}\right)_{3}\right\}_{4}\left(\mathrm{H}_{2} \mathrm{O}\right)_{2}\right] \mathrm{BF}_{4}$ were synthesized by literature methods $[6,7]$. Other reagents and solvents were purchased from commercial sources and were used without further purification.

$\left(\mathrm{PPh}_{4}\right)_{n}\left[\mathrm{Ru}_{2}\left(\mathrm{O}_{2} \mathrm{CCH}_{3}\right)_{4} \mathrm{Ni}(\mathrm{CN})_{4}\right]_{n} \cdot n \mathrm{H}_{2} \mathrm{O}(\mathbf{1})$

Tetraphenylphosphonium chloride $(6.7 \mathrm{mg}, 0.018 \mathrm{mmol})$ and potassium tetracyanidonickelate(II) $(2.3 \mathrm{mg}, 0.0088$ mmol) were dissolved in $4 \mathrm{~mL}$ of $\mathrm{H}_{2} \mathrm{O}$, respectively. To an aqueous solution $(2 \mathrm{~mL})$ of $\left[\mathrm{Ru}_{2}\left(\mathrm{O}_{2} \mathrm{CCH}_{3}\right)_{4}\left(\mathrm{H}_{2} \mathrm{O}\right)_{2}\right] \mathrm{BF}_{4}$ $(10.0 \mathrm{mg}, 0.0178 \mathrm{mmol})$ were added these solutions, stirred for $1 \mathrm{~min}$. The resulting precipitate was filtered, washed with $9 \mathrm{~mL}$ of water, and dried in vacuo. Yield: $5.4 \mathrm{mg}(62 \%)$. Anal. Found: C, 45.15; H, 3.44; N, 5.87\%. Calcd. for $\mathrm{C}_{36} \mathrm{H}_{34} \mathrm{~N}_{4} \mathrm{NiO}_{9} \mathrm{PRu}_{2}: \mathrm{C}, 45.11 ; \mathrm{H}, 3.58 ; \mathrm{N}, 5.85 \%$. IR (KBr): v(Ar-H) 3060, 3100, v(CN) 2130, $v_{\text {as }}\left(\mathrm{CO}_{2}^{-}\right) 1442, v_{\mathrm{s}}\left(\mathrm{CO}_{2}^{-}\right)$ 1403. Diffuse reflectance spectrum: $\lambda_{\text {max }} 338,452,1058,1670 \mathrm{~nm}$. 
$\left(\mathrm{PPh}_{4}\right)_{n}\left[\mathrm{Ru}_{2}\left\{\mathrm{O}_{2} \mathrm{CC}\left(\mathrm{CH}_{3}\right)_{3}\right\}_{4}\right]_{3 n}\left[\mathrm{Ni}(\mathrm{CN})_{4}\right]_{2 n} \cdot 2 n \mathrm{H}_{2} \mathrm{O}(2)$

Tetraphenylphosphonium chloride $(5.1 \mathrm{mg}, 0.014 \mathrm{mmol})$ and potassium tetracyanidonickelate(II) $(1.8 \mathrm{mg}$, $0.0070 \mathrm{mmol})$ were dissolved in $5 \mathrm{~mL}$ of $\mathrm{H}_{2} \mathrm{O}$, respectively. To an aqueous solution $(5 \mathrm{~mL})$ of $\left.\left[\mathrm{Ru}_{2} \mathrm{O}_{2} \mathrm{CC}\left(\mathrm{CH}_{3}\right)_{3}\right\}_{4}\left(\mathrm{H}_{2} \mathrm{O}\right)_{2}\right]$ $\mathrm{BF}_{4}(10.0 \mathrm{mg}, 0.0137 \mathrm{mmol})$ were added these solutions, stirred for $1 \mathrm{hr}$. The resulting precipitate was filtered, washed with $9 \mathrm{~mL}$ of water, and dried in vacuo. Yield: $6.5 \mathrm{mg}(77 \%)$. Anal. Found: C, 43.70; H, 5.29; N, 4.46\%. Calcd. for $\mathrm{C}_{92} \mathrm{H}_{132} \mathrm{~N}_{8} \mathrm{Ni}_{2} \mathrm{O}_{26} \mathrm{PRu}_{6}$ : C, 43.83; $\mathrm{H}, 5.28 ; \mathrm{N}, 4.45 \%$. IR (KBr): v(Ar-H) 3061, 3085, v(CN) 2128, $v_{\mathrm{as}}\left(\mathrm{CO}_{2}^{-}\right) 1487$, $v_{\mathrm{s}}\left(\mathrm{CO}_{2}^{-}\right) 1421$. Diffuse reflectance spectrum: $\lambda_{\max } 346,454,1082,1676 \mathrm{~nm}$.

Measurements: Elemental analyses for carbon, hydrogen, and nitrogen were done using a Thermo-Finnigan FLASH EA1112 series CHNO-S analyzer. Infrared spectra were measured with a JASCO MFT-2000 FT-IR Spectrometer in the $4000-600 \mathrm{~cm}^{-1}$ region. Electronic spectra were measured with a Shimadzu UV-vis-NIR Recording Spectrophotometer (Model UV-3100). Magnetic susceptibilities were measured with a Quantum Design MPMS-XL7 SQUID susceptometer operating at a magnetic field of $0.5 \mathrm{~T}$ over a range of 4.5-300 K. The susceptibilities were corrected for the diamagnetism of the constituent atoms using Pascal's constants. The effective magnetic moments were calculated from the equation $\mu_{\text {eff }}=2.828 \sqrt{ } \chi_{\mathrm{M}} T$, where $\chi_{\mathrm{M}}$ is the molar magnetic susceptibility per mole of dinuclear ruthenium(II,III) unit.

\section{Results and discussion}

Reaction of the mixed-valent dinuclear ruthenium(II,III) acetate and ruthenium(II,III) pivalate with tetracyanidonickelate(II) ion in the presence of tetraphenylphosphonium ion gave orange and brown precipitates, respectively. The formulation of the mixed-metal systems of dinuclear ruthenium(II,III) carboxylate with tetracyanidonickelate(II), $\left(\mathrm{PPh}_{4}\right)_{n}\left[\mathrm{Ru}_{2}\left(\mathrm{O}_{2} \mathrm{CCH}_{3}\right)_{4} \mathrm{Ni}(\mathrm{CN})_{4}\right]_{n} \cdot n \mathrm{H}_{2} \mathrm{O}$ (1) and $\left(\mathrm{PPh}_{4}\right)_{n}\left[\mathrm{Ru}_{2}\left\{\mathrm{O}_{2} \mathrm{CC}\left(\mathrm{CH}_{3}\right)_{3}\right\}_{4}\right]_{3 n}\left[\mathrm{Ni}(\mathrm{CN})_{4}\right]_{2 n} \cdot$ $2 \mathrm{nH}_{2} \mathrm{O}$ (2), was confirmed by the elemental analyses, infrared and electronic spectra, and temperature dependence of magnetic susceptibility data $(4.5-300 \mathrm{~K})$.

In the infrared spectra, two strong bands were observed at 1442 and $1403 \mathrm{~cm}^{-1}$ assignable to asymmetric and symmetric stretching vibrations of the syn-syn acetate bridges, respectively, for $\mathbf{1}$, whereas two strong bands observed at 1487 and $1421 \mathrm{~cm}^{-1}$ assignable to asymmetric and symmetric stretching vibrations of the syn-syn pivalate bridges, respectively, for 2 (Figure 1). The sharp bands at $2130 \mathrm{~cm}^{-1}$ in $\mathbf{1}$ and $2128 \mathrm{~cm}^{-1}$ in 2 may be attributed to $v(\mathrm{CN})$ stretching band of the tetracyanidonickelate(II) ion. These bands appeared at a little higher energy region compared with that of $\mathrm{K}_{2}\left[\mathrm{Ni}(\mathrm{CN})_{4}\right]\left(\mathrm{v}(\mathrm{CN}): 2125 \mathrm{~cm}^{-1}\right)$, suggesting the bridging of the tetracyanidonickelate(II) to the dinuclear ruthenium carboxylate unit [38,39]. The C-H stretching vibrations of aromatic rings were observed at 3100 and $3060 \mathrm{~cm}^{-1}$ for $\mathbf{1}$ and at 3085 and $3061 \mathrm{~cm}^{-1}$ for 2 , respectively, in agreement with the presence of the tetraphenylphosphonium ions.

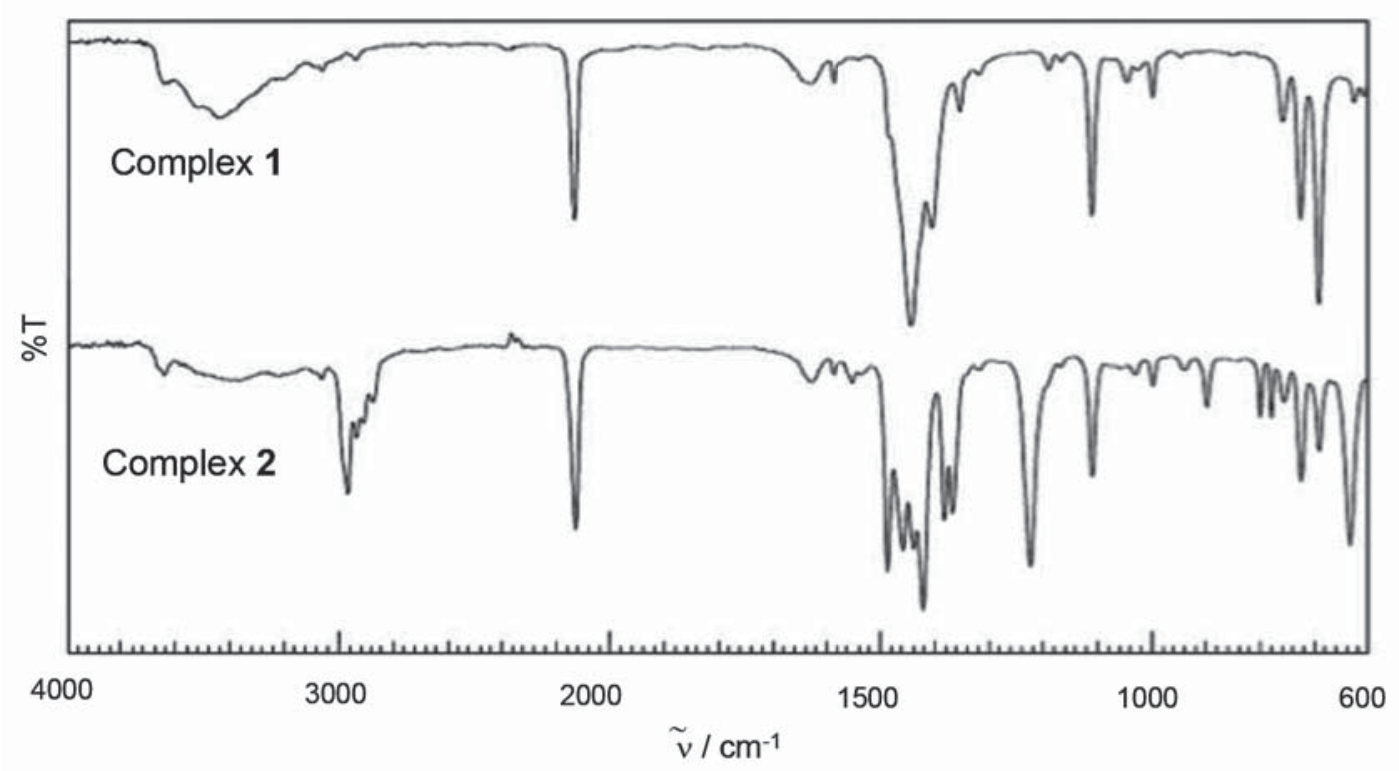

Figure 1. Infrared spectra of 1 and 2. 


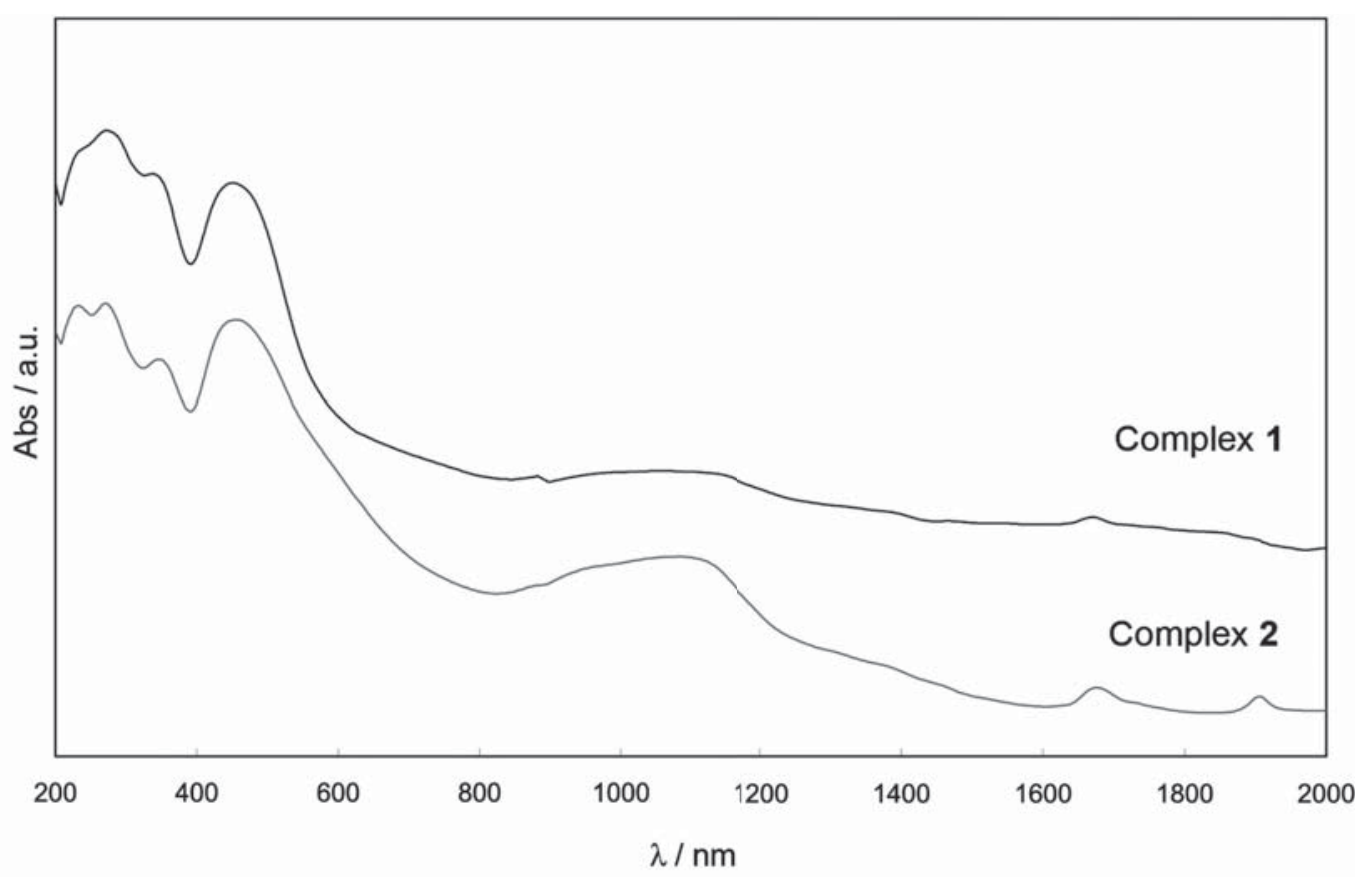

Figure 2. Diffused reflectance spectra of 1 and 2.

The diffused reflectance spectra of $\mathbf{1}$ and $\mathbf{2}$ are shown in Figure 2. The paddlewheel-type dinuclear structure of the mixed-valent dinuclear ruthenium(II,III) carboxylate can be considered to be maintained in these mixed-metal complexes, because the spectra contain the characteristic bands of dinuclear ruthenium(II,III) carboxylate. A weak broad absorption band around 1058 and $1670 \mathrm{~nm}$ in solid is typical for ruthenium(II,III) carboxylates and can be attributed to a $\delta\left(\mathrm{Ru}_{2}\right) \rightarrow \delta^{*}\left(\mathrm{Ru}_{2}\right)$ and $\pi^{*}\left(\mathrm{Ru}_{2}\right) \rightarrow \delta^{*}\left(\mathrm{Ru}_{2}\right)$ transitions, respectively, within ruthenium(II,III) dinuclear core [8]. A medium band at $452 \mathrm{~nm}$ may be due to $\pi\left(\mathrm{RuO}, \mathrm{Ru}_{2}\right) \rightarrow \pi^{*}\left(\mathrm{Ru}_{2}\right)$ transition [11,12]. The spectra contain another feature due to the presence of tetracyanidonickelate(II) moiety. The bands at 338 and $452 \mathrm{~nm}$ can be assigned to the ${ }^{1} \mathrm{~A}_{1 \mathrm{~g}} \rightarrow{ }^{1} \mathrm{~A}_{2 \mathrm{~g}}$ and ${ }^{1} \mathrm{~A}_{1 \mathrm{~g}} \rightarrow{ }^{1} \mathrm{~B}_{2 \mathrm{~g}}$ transitions, respectively, of the tetracyanidonickelate(II) moiety [38,39]. Similar spectral feature was observed for 2: $1082\left(\delta\left(\mathrm{Ru}_{2}\right) \rightarrow \delta^{*}\left(\mathrm{Ru}_{2}\right)\right), 1676\left(\pi^{*}\left(\mathrm{Ru}_{2}\right) \rightarrow \delta^{*}\left(\mathrm{Ru}_{2}\right)\right), 454\left(\pi\left(\mathrm{RuO}, \mathrm{Ru}_{2}\right) \rightarrow \pi^{*}\left(\mathrm{Ru}_{2}\right),{ }^{1} \mathrm{~A}_{1 \mathrm{~g}}(\mathrm{Ni}) \rightarrow{ }^{1} \mathrm{~A}_{2 \mathrm{~g}}(\mathrm{Ni})\right)$, $346\left({ }^{1} \mathrm{~A}_{1 \mathrm{~g}}(\mathrm{Ni}) \rightarrow{ }^{1} \mathrm{~B}_{2 \mathrm{~g}}(\mathrm{Ni})\right) \mathrm{nm}$

Temperature dependence of effective magnetic moments is shown in Figure 3.

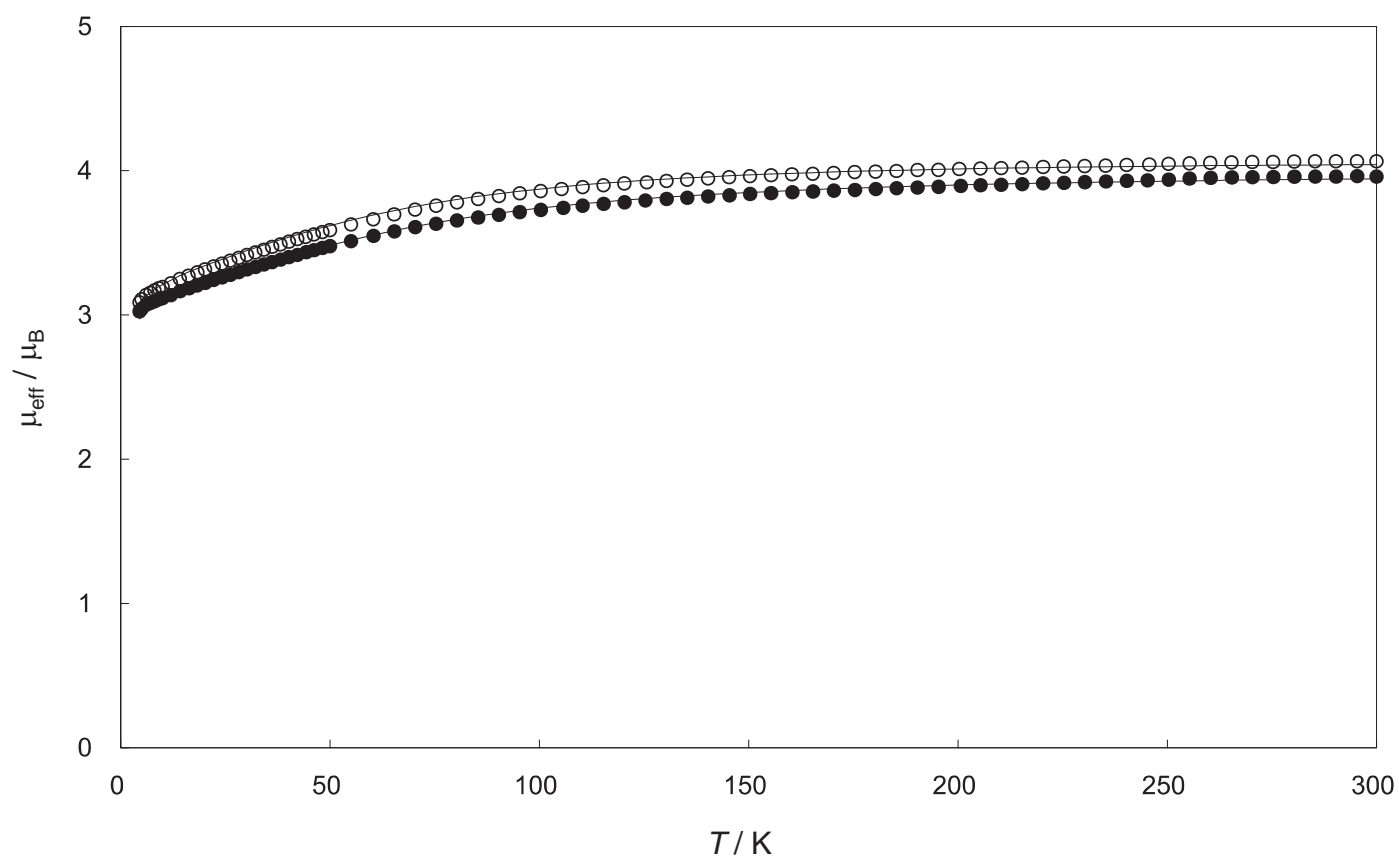

Figure 3. Temperature dependence of the magnetic moments of $1(\bullet)$ and $2(\circ)$. 
The magnetic moments of 1 and 2 are 3.98 and $4.07 \mu_{\mathrm{B}}$, respectively, at $300 \mathrm{~K}$ per dinuclear ruthenium(II,III) unit, which are slightly higher than the spin-only value of $S=3 / 2\left(3.87 \mu_{\mathrm{B}}\right)$. The magnetic moments gradually decrease with lowering of temperature until reaching 3.02 and $3.09 \mu_{\mathrm{B}}$, respectively, at $4.5 \mathrm{~K}$, being typical of dinuclear ruthenium(II,III) carboxylates [3-5].

The magnetic data were analyzed by a molecular field approximation [40] considering the ZFS effect to estimate the magnitude of the antiferromagnetic interaction $[9,10]$. This approximation has been commonly applied for dinuclear ruthenium(II,III) carboxylates using the following equations:

$\chi^{\prime}=\chi /\left\{1-\left(2 \mathrm{zJ} / N g^{2} \mu_{\mathrm{B}}^{2}\right) \chi\right\}$

$\chi=\left(\chi_{/ /}+2 \chi_{\perp}\right) / 3$

$\chi_{/ /}=\left(N g^{2} \mu_{\mathrm{B}}^{2} / k T\right)[1+9 \exp (-2 D / k T)] / 4\{1+\exp (-2 D / k T)\}$

$\chi_{\perp}=\left(N g^{2} \mu_{\mathrm{B}}^{2} / k T\right)[4+(3 k T / D)\{1-\exp (-2 D / k T)\}] / 4\{1+\exp (-2 D / k T)\}$

where $z J$ is the exchange integral multiplied by the number of interacting neighbors, $\chi$ is the magnetic susceptibility of the individual dinuclear unit, and $D$ is the ZFS parameter.

The $D$ parameter was fixed at $75 \mathrm{~cm}^{-1}$ which is a normal value for dinuclear ruthenium(II,III) carboxylates [3]. The $g$ value was treated as isotropic. Best fitting curve was obtained with the parameters; $z J=-0.20 \mathrm{~cm}^{-1}, g=2.06$ for 1 . The similar parameters $z J=-0.20 \mathrm{~cm}^{-1}, g=2.09$ were obtained for 2 . These results show that a weak antiferromagnetic interaction is operating between the dinuclear ruthenium units, being consistent with a long separation of the dinuclear ruthenium units through the tetracyanidonickelate(II) bridge for the present complexes.

From the above results, we can assume a chain structure with an alternated arrangement of dinuclear ruthenium units and tetracyanidonickelate(II) ions shown in Figure 4 (a) for 1, whereas one- or two-dimensional array of dinuclear ruthenium units and tetracyanidonickelate(II) ions such as Figures 4 (b) and 4 (c) for 2. There are two types of CN groups for the tetracyanidonickelate(II) moieties: bridging and non-coordinating. We can see the overlapping of these $\mathrm{CN}$ stretching bands in the infrared spectra as shown in Figure 5.

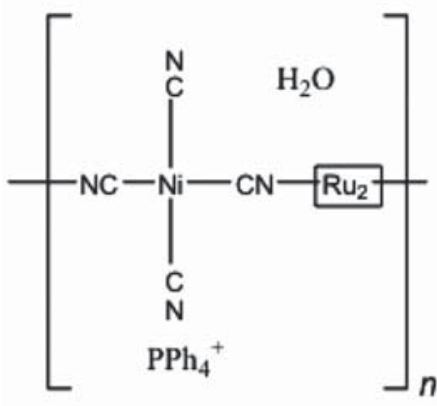

(a)

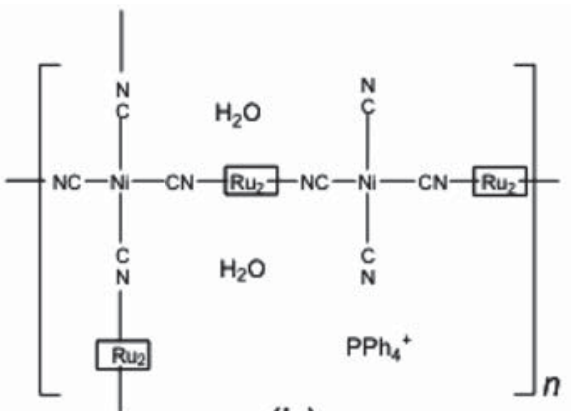

(b)

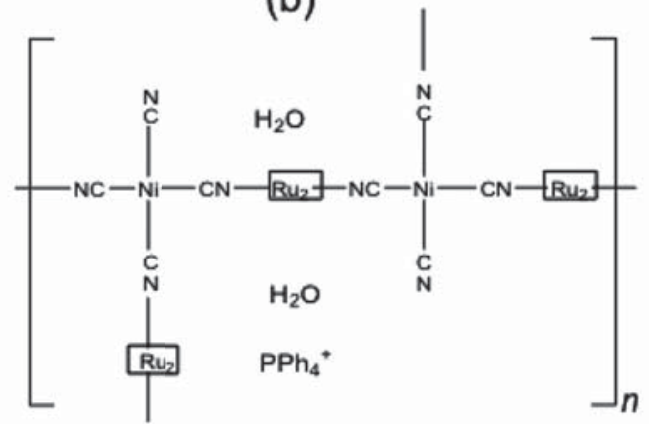

(c)

Figure 4. Proposed structures (a) for 1 and (b) and (c) for 2, respectively. The $\mathrm{Ru}_{2}$ unit denotes the dinuclear ruthenium carboxylate. 


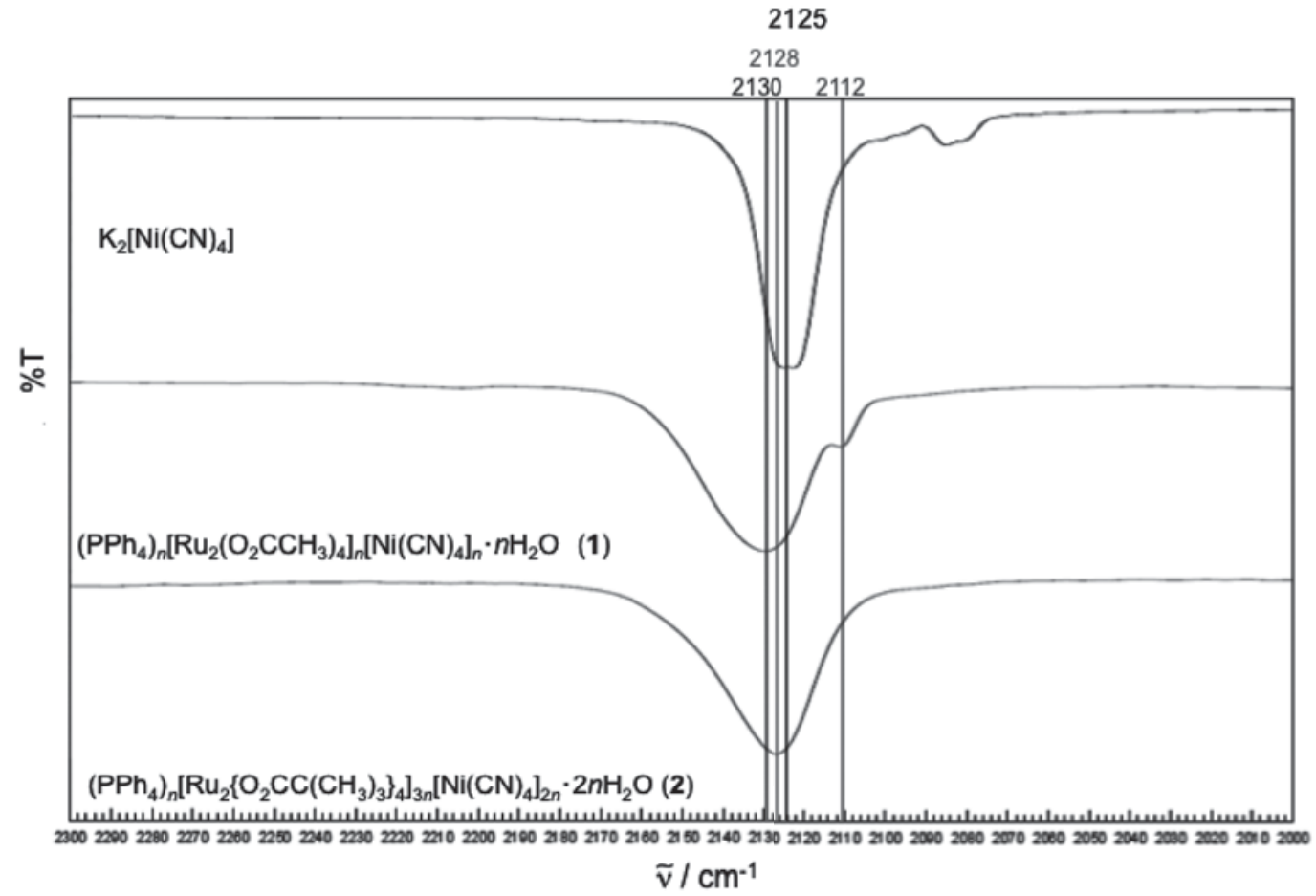

Figure 5. Infrared spectra of $\mathrm{K}_{2}\left[\mathrm{Ni}(\mathrm{CN})_{4}\right]$ and the present complexes in the $\mathrm{CN}$ stretching band region.

\section{Conclusions}

By using tetracyanidonickelate(II), the preparation of the mixed-metal chain complexes of dinuclear ruthenium(II,III) carboxylate, $\left(\mathrm{PPh}_{4}\right)_{n}\left[\mathrm{Ru}_{2}\left(\mathrm{O}_{2} \mathrm{CCH}_{3}\right)_{4} \mathrm{Ni}(\mathrm{CN})_{4}\right]_{n} \cdot n \mathrm{H}_{2} \mathrm{O} \quad$ (1) and $\left(\mathrm{PPh}_{4}\right)_{n}\left[\mathrm{Ru}_{2}\left\{\mathrm{O}_{2} \mathrm{CC}\left(\mathrm{CH}_{3}\right)_{3}\right\}_{4}\right]_{3 n}\left[\mathrm{Ni}(\mathrm{CN})_{4}\right]_{2 n} \cdot 2 n \mathrm{H}_{2} \mathrm{O}(2)$, was achieved successfully. The analytical data, infrared spectra, UV-vis-NIR spectra, and temperature dependence of magnetic susceptibilities are consistent with one- or two-dimensional chain structures with an alternated arrangement of dinuclear ruthenium units and tetracyanidonickelate(II) ions. In accordance with the structural feature, a weak antiferromagnetic interaction through the tetracyanidonickelate(II) ion was observed for the present complexes.

\section{Acknowledgements}

The present work was partially supported by Grant-in-Aid for Scientific Research No. 26410080 from the Ministry of Education, Culture, Sports, Science and Technology (MEXT, Japan) and the NEXT-Supported Program for the Strategic Research Foundation at Private Universities, 2010-2014.

\section{References}

1. Cotton, F.A.; Murillo, C.A.; Walton, R.A. Multiple Bonds between Metal Atoms. 3rd ed. Springer Science and Business Media: New York, 2005, 818 p.

2. Mikuriya, M. Copper(II) acetate as a motif for metal-assembled complexes. Bulletin of the Japanese Society of Coordination Chemistry, 2008, 52, pp. 17-28 (in Japanese).

3. Mikuriya, M.; Yoshioka, D.; Handa, M. Magnetic interactions in one-, two-, and three-dimensional assemblies of dinuclear ruthenium carboxylates. Coordination Chemistry Reviews, 2006, 250, pp. 2194-2211.

4. Aquino, M.A.S. Recent developments in the synthesis and properties of dinuclear tetracarboxylates. Coordination Chemistry Reviews, 2004, 248, pp. 1025-1045.

5. Aquino, M.A.S. Diruthenium and diosmium tetracarboxylates: synthesis, physical properties and applications. Coordination Chemistry Reviews, 1998, 170, pp. 141-202.

6. Stephenson, T. A.; Wilkinson, G. New ruthenium carboxylate complexes, Journal of inorganic and nuclear Chemistry, 1966, 28, pp. 2285-2291.

7. Barral, M. C.; Jiménez-Aparicio, R.; Priego, J. L.; Royer, E.C. Polyhedron, 1992, pp. 2209-2215.

8. Norman, G.J.; Renzoni, G.E.; Case, D.A. Electronic strucutre of $\mathrm{Ru}_{2}\left(\mathrm{O}_{2} \mathrm{CR}\right)_{4}{ }^{+}$and $\mathrm{Rh}_{2}\left(\mathrm{O}_{2} \mathrm{CR}\right)_{4}^{+}$complexes, Journal of the American Chemical Society, 1979, 101, pp. 5256-5267.

9. Telser, J.; Drago, R.S. Reinvestigation of the electronic and magnetic properties of ruthenium butyrate chloride. Inorganic Chemistry, 1984, 23, pp. 3114-3120. 
10. Telser, J.; Drago, R.S. Correction: Reinvestigation of the electronic and magnetic properties of ruthenium butyrate chloride. Inorganic Chemistry, 1985, 24(26), p. 4765.

11. Miskowski, V.M.; Loehr, T.M.; Gray, H.B. Electronic and vibrational spectra of $\mathrm{Ru}_{2}(\text { carboxylate })_{4}{ }^{+}$complexes. Characterization of a high spin metal-metal ground state. Inorganic Chemstry, 1987, 26, pp. 1098-1108.

12. Miskowski, V.M.; Gray, H.B. Electronic spectra of $\mathrm{Ru}_{2}$ (carboxylate) $)^{4+}$ complexes. Higher energy electronic excited states, Inorganic Chemistry, 1988, 27(14), pp. 2501-2506.

13. Ishida, H.; Handa, M.; Mikuriya, M. Synthesis and crystal structure of aqua adduct of dinuclear ruthenium(II,III) 3,4,5-tri (ethoxy- $d_{5}$ ) benzoate tetrafluoroborate, X-Ray Structure Analysis Online, 2014, 30, pp. 9-10.

14. Sayama, Y.; Handa, M.; Mikuriya, M.; Nukada, R.; Hiromitsu, I.; Kasuga, K. Mixed-valent ruthenium pivalate and its nitroxide adduct. Coordination Chemistry at the Turn of the Century. Ed. by Ondrejovic, G.; Sirota, A. Slovak Technical University Press: Bratislava, 1999; pp. 447-452.

15. Sayama, S.; Handa, M.; Mikuriya, M.; Hiromitsu, I.; Kasuga, K. Chain compound of mixed-valent ruthenium dimers linked by hydrogen-bonding between the axially coordinated nitronyl nitroxide and water molecules, Chemistry Letters, 1999, pp. 453-454.

16. Handa, M.; Yoshioka, D.; Sayama, Y.; Shiomi, K.; Mikuriya, M.; Hiromitsu, I.; Kasuga, K. A new "dimer-ofdimers" complex derived from axial coordination of 7,7,8,8-tetracyanoquinodimethane to Ru(II,III) cation dimer, Chemistry Letters, 1999, pp. 1033-1034.

17. Yoshioka, D.; Handa, M.; Azuma, H.; Mikuriya, M.; Hiromitsu, I.; Kasuga, K. Synthesis and magnetic property of adducts of ruthenium(II,III) pivalate with 9,10-anthraquinone, Molecular Crystal and Liquid Crystal, 2000, 342, pp. 133-138.

18. Sayama, Y.; Handa, M.; Mikuriya, M.; Hiromitsu, I.; Kasuga, K. Structures and magnetic properties of ruthenium(II,III) pivalate cation dimers axially coordinated by pyridyl nitronyl nitroxide radicals through their pyridyl nitrogen atoms, Bulletin of the Chemical Society of Japan, 2000, 73, pp. 2499-2504.

19. Sayama, Y.; Handa, M.; Mikuriya, M.; Hiromitsu, I.; Kasuga, K. Synthesis and magnetic properties of ruthenium(II,III) pivalate dimers axially coordinated by nitronyl nitroxide radicals $\left[\mathrm{Ru}_{2}\left(\mathrm{O}_{2} \mathrm{CCMe}_{3}\right)_{4}(\mathrm{~L})_{2}\right] \mathrm{BF}_{4}$ and $\left[\left\{\mathrm{Ru}_{2}\left(\mathrm{O}_{2} \mathrm{CCMe}_{3}\right)_{4}(\mathrm{~L})_{2}\right\}\left\{\mathrm{Ru}_{2}\left(\mathrm{O}_{2} \mathrm{CCMe}_{3}\right)_{4}\left(\mathrm{H}_{2} \mathrm{O}\right)_{2}\right\}\right]_{n}\left(\mathrm{BF}_{4}\right)_{2 n}, \mathrm{~L}=$ 2,4,4,5,5-pentamethyl-4,5-dihydro-1H-imidazol1-oxyl-3- $\mathrm{N}$-oxide and 2-ethyl-4,4,5,5-tetramethyl-4,5-dihydro- $1 \mathrm{H}$-imidazol-1-oxyl-3- $\mathrm{N}$-oxide, Bulletin of the Chemical Society of Japan, 2003, 76, pp. 769-779.

20. Handa, M.; Yoshioka, D.; Mikuriya, M.; Hiromitsu, I.; Kasuga, K. Coordination polymers of ruthenium(II) acetate with pyrazine, 4,4'-bipyridine, and 1,4-diazabicyclo[2.2.2]octane, Molecular Crystal and Liquid Crystal, 2002, 376, pp. 257-262.

21. Yoshioka, D.; Mikuriya, M.; Handa, M. Synthesis and characterization of polynuclear chain and tetranuclear complexes of mixed-valent ruthenium(II,III) pivalate with $N, N^{\prime}$-didentate ligands. Bulletin of the Chemical Society of Japan, 2004, 77, pp. 2205-2211.

22. Handa, M.; Ishida, H.; Ito, K.; Adachi, T.; Ikeue, T.; Hiromitsu, I.; Mikuriya, M.; Kasuga, K. Synthesis and magnetic properties of polymeric complexes containing ruthenium(II)-ruthenium(III) tetracarboxylato units linked by cyanato, thiocyanato, and selenocyanato lignads. Chemical Papers, 2008, 62, pp. 410-416.

23. Yoshioka, D.; Handa, M.; Mikuriya, M.; Kasuga, K. Coordination polymers of ruthenium pivalate dimer with tetracyanoethylene, 7,7,8,8-tetracyanoquinodimethane, and 2,5-dimethyl- $N, N^{\prime}$-dicyanobenzoquinonediimine. Advances in Coordination, Bioinorganic and Inorganic Chemistry. ed. by Melnik, M.; Sima, J.; Tatarko, M. Slovak Technical University Press: Bratislava, 2005; pp. 218-223.

24. Mikuriya, M.; Tanaka, K.; Handa, M.; Hiromitsu, I.; Yoshioka, D.; Luneau, D. Adduct complexes of ruthenium(II,III) propionate dimer with pyridyl nitroxides, Polyhedron, 2005, 24, pp. 2658-2664.

25. Ishida, H.; Handa, M.; Hiromitsu, I.; Ujiie, S.; Mikuriya, M. Synthesis and magnetic properties of polymer complexes of ruthenium(II,III) 3,4,5-trioctanoxybenzoate linked by chloro and cyanato ligands with liquidcrystalline behavior. Achievements in Coordination, Bioinorganic and Applied Inorganic Chemistry. ed. by Melnik, M.; Sima, J.; Tatarko, M. Slovak Technical University Press: Bratislava, 2007; pp. 121-127.

26. Ishida, H.; Handa, M.; Hiromitsu, I.; Mikuriya, M. Synthesis, magnetic and spectral properties, and crystal structure of mixed-valence ruthenium(II,III) 3,4,5-tributanoxybenzoate. Insights into Coordination, Bioinorganic and Applied Inorganic Chemistry. Ed. by Melnik, M.; Segl'a, P.; Tatarko, M. Slovak Technical University Press: Bratislava, 2009; pp. 197-203.

27. Ishida, H.; Handa, M.; Ikeue, T.; Taguchi, J.; Mikuriya, M. Synthesis, crystal structure, and ${ }^{1} H$ NMR spectra of a chloride-bridged chain complex of dinuclear ruthenium(II,III) 3,4,5-tri(ethoxy- $d_{5}$ )benzoate. Chemical Papers, 2010, 64, pp. 767-775.

28. Ishida, H.; Handa, M.; Hiromitsu, I.; Mikuriya, M. Fastener effect on magnetic properties of chain compounds of dinuclear ruthenium carboxylates. Chemical Papers, 2013, 67, pp. 743-750. 
29. Ikeue, T.; Karino, K.; Iida, M.; Yamaji, T.; Hiromitsu, I.; Sugimori, T.; yoshioka, D.; Mikuriya, M.; Handa, M. Structural, magnetic, and ${ }^{1} \mathrm{H}$ NMR spectral study on lantern-type cis- and trans-diruthenium(II,III) complexes with two formamidinato and two acetato bridges. Inorganic Chemistry Communications, 2013, 33, pp. 133-137.

30. Yoshioka, D.; Mikuriya, M.; Handa, M. Molecular-assembled complexes of mixed-valent ruthenium dimer with hexacyanoferrate(III) and hexacyanocobaltate(III) ions, Chemistry Letters, 2002, 31, pp. 1044-1045.

31. Vos, T.E.; Liao, Y.; Shum, W.W.; Her, J.-H.; Stephens, P.W.; Reiff, W.M.; Miller, J.S. Diruthenium tetraacetate monocation, $\left[\mathrm{Ru}^{\mathrm{II} / \mathrm{III}}\left(\mathrm{O}_{2} \mathrm{CMe}\right)_{4}\right]^{+}$, building blocks for 3-D molecule-based magnets, Journal of the American Chemical Society, 2004, 126, pp. 11630-11639.

32. Vos, T.E.; Miller, J.S. Building blocks for 2D molecule-based magnets: the diruthenium tetrapivalate monocation $\left[\mathrm{Ru}_{2}^{\mathrm{II} / I I}\left(\mathrm{O}_{2} \mathrm{CtBu}\right)_{4}\right]^{+}$, Angewandte Chemie International Edition, 2005, 44, pp. 2416-2419.

33. Miller, J. S. Magnetically ordered molecule-based assemblies, Dalton Transaction, 2006, pp. 2742-2949.

34. Kennon, B.S.; Her, J.-H.; Stephens, P.W.; Miller, J.S. Diruthenium teracarbonate trianion, $\left[\mathrm{Ru}^{\mathrm{II} / \mathrm{III}}{ }_{2}\left(\mathrm{O}_{2} \mathrm{CO}\right)_{4}\right]^{3-}$, based molecule-based magnets: three-dimensional network structure and two-dimensional magnetic ordering, Inorganic Chemistry, 2009, 48, pp. 6117-6123.

35. Kennon, B.S.; Miller, J.S. Observation of magnetic ordering for layered (2-D) potassium diruthenium tetracrbonate, $\mathrm{K}_{3}\left[\mathrm{Ru}^{\mathrm{II} / \mathrm{III}}\left(\mathrm{O}_{2} \mathrm{CO}\right)_{4}\right]$ : a rare second row transition, Inorganic Chemistry, 2010, 49, pp. 5542-5545.

36. Matoga, D.; Mikuriya, M.; Handa, M.; Szklarzewicz, J. Self-assembly of Mixed-valent ruthenium(II,III) pivalate and octacyanotungstate(V) building blocks. Chemistry Letters, 2005, 34, pp. 1550-1551.

37. Mikuriya, M.; Yoshioka, D.; Borta, A.; Luneau, D.; Matoga, D.; Szklarzewicz, J.; Handa, M. Molecule-based magnetic materials based on dinuclear ruthenium carboxylate and octacyanotungstate. New Journal of Chemistry, 2011, 35, pp. 1226-1233.

38. Zhan, S.-Z.; Guo, D.; Zhang, X.-Y.; Du, C.-X.; Zhu, Y; Yang R.-N. The design, assembly, properties and crystal structure of one-dimensional polymeric cyanide-bridged nickel(II)/nickel(II) complexes, Inorganica Chimica Acta, 2000, 298, pp. 57-62.

39. Smekal,Z.; Cisarova, I.; Mrozinski, J. Cyano-bridged bimetallic complexes of copper(II) with tetracyanonickelate(II). Crystal structure of [Cu(dpt)Ni(CN) $)_{4}$, Polyhedron, 2001, 20, pp. 3301-3306.

40. O'Connor, C.J. Magnetochemistry-Advances in theory and experimentation, Progress in Inorganic Chemistry, 1982, 29, pp. 203-283.

41. Terazzi, E.; Torelli, S.; Bernardinelli, G.; Rivera, J.-P.; Bénech, J.-M.; Bourgogne, C.; Donnio, B.; Guillon, D.; Imbert, D.; Bünzli, J.-C. G.; Pinto, A.; Jeannerat, D.; Piruet, C. Molecular control of macroscopic cubic, columnar, and lamellar organizations in luminescent lanthanide-containing thermotropic liquid crystals, Journal of the American Chemical Society, 2005, 127, pp. 888-903. 